\title{
Clozapine Management in Schizophrenia Inpatients: A 5-Year Prospective Observational Study of Its Safety and Tolerability Profile
}

\author{
Renato de Filippis (D) \\ Raffaele Gaetano (D) \\ Georgios Schoretsanitis (iD ${ }^{2}$ \\ Giuseppe Verde' \\ Cesare Anthony Oliveti ${ }^{3}$ \\ John M Kane iD $2,4,5$ \\ Cristina Segura-Garcia (iD) ${ }^{6}$ \\ Pasquale De Fazio (D) \\ 'Psychiatry Unit, Department of Health \\ Sciences, University Magna Graecia of \\ Catanzaro, Catanzaro, Italy; ${ }^{2}$ The Zucker \\ Hillside Hospital, Psychiatry Research, \\ Northwell Health, Glen Oaks, NY, USA; \\ ${ }^{3}$ Correnti - Centri Assistenziali Mons. \\ Oliveti, Crotone, Italy; ${ }^{4}$ Department of \\ Psychiatry, Zucker School of Medicine at \\ Northwell/Hofstra, Hempstead, NY, \\ USA; ${ }^{5}$ Center for Psychiatric \\ Neuroscience, Feinstein Institute for \\ Medical Research, Manhasset, NY, USA; \\ ${ }^{6}$ Psychiatry Unit, Department of Medical \\ and Surgical Sciences, University Magna \\ Graecia of Catanzaro, Catanzaro, Italy
}

Correspondence: Pasquale De Fazio Psychiatry Unit, Department Health Sciences, University Magna Graecia of Catanzaro, Viale Europa 88100,

Catanzaro, Italy

$\mathrm{Tel} / \mathrm{Fax}+39096 \mid 712393$

Email defazio@unicz.it
Background: Clozapine is well known for its efficacy and clinical superiority compared to other antipsychotics in treatment-resistant schizophrenia (TRS). However, it is frequently underutilized worldwide because of its acute adverse events, as well as for its long-term cardiometabolic and hematological consequences.

Objective: The aim of the study was to evaluate 5-year safety in chronic TRS inpatients with continuous clozapine use.

Methods: Patients with TRS and clozapine treatment were evaluated for 5 years. All participants were assessed using the Brief Psychiatric Rating Scale (BPRS), Glasgow Antipsychotic Side-effect Scale for Clozapine (GASS-C), Social Performance Scale (PSP) and Short Portable Mental Status Questionnaire (SPMSQ). Clinical, cardiometabolic and hematological data were collected periodically. General linear models (GLM) repeated measures controlling for CLZ dose were utilized to determine differences in variables across the time.

Results: Overall, 189 inpatients were screened for study participation. The final sample included twenty-one TRS patients (16 males, 76\%) with an average age of 57.6 years, all with 5-year continuous use of clozapine (mean dose $266 \mathrm{mg} /$ day). There was not a significant effect of time on BPRS $(p=0.774)$, PSP $(\mathrm{p}=0.855)$ and SPMSQ $(\mathrm{p}=0.066)$; differences remained not significant after controlling for CLZ dose $(p=0.585, p=0.467$ and $p=0.105$, respectively). No changes were found in blood and clinical parameters except for red blood cell count, which decreased over time $\left(p=0.024 ; \eta^{2}=0.952\right)$. Patients reported a significant BMI decrease $(-8.98 \mathrm{~kg}, p=0.008)$ between baseline and 5 years last observation.

Conclusion: The findings show how the application of a structured dietary, clinical and therapeutic monitoring program in psychiatric care facilities could allow the safe and effective long-term cardiometabolic and hematological management of clozapine. The unique role that clozapine plays in the current treatment of patients with TRS requires greater clinical awareness. Although its acute and chronic side effects are notorious, its safety management is feasible and broadens its potential practical application.

Keywords: clozapine, psychiatric care facilities, safety, schizophrenia, tolerability, treatment-resistant schizophrenia

\section{Introduction}

Schizophrenia (SCZ) is a complex, severe and pervasive mental disorder characterized by an early onset, tendency for chronicity, impairment of social and personal functioning, and heterogeneous combination of symptoms. ${ }^{1}$ The main symptoms of SCZ can be divided into four domains: positive, negative, cognitive 
and affective symptoms. ${ }^{2}$ Treatment management in SCZ is still particularly challenging and represents a sensitive balance between efficacy and effectiveness on one side, and tolerability and safety on the other. ${ }^{3-5}$ Antipsychotics are the condicio sine qua non of treatment, ${ }^{6}$ supported by the dopaminergic hypothesis of $\mathrm{SCZ}^{7}$, but they are associated with important adverse events that can cause reduced quality of life, serious disability and even lifethreatening conditions. ${ }^{8}$ Therefore, decisions as to when and which antipsychotic to choose, and what side effects are acceptable in the cost-benefit ratio can be challenging. ${ }^{9-12}$

The history of pharmacotherapy in SCZ patients was transformed by the introduction of chlorpromazine in the '50s. ${ }^{13}$ In the following years the development of new antipsychotics of the same or other generations has improved the response to the treatment and the prognosis of SCZ. ${ }^{14}$ However, it quickly became clear that some patients showed little or no clinical response to firstand second-line treatment with several different antipsychotics, with the only exemption of clozapine. ${ }^{15}$ In late ' 80 s clozapine has shown to have superior clinical efficacy in patients who did not respond to other antipsychotics. ${ }^{16}$ Currently, clozapine is still the only medication with established efficacy and clinical superiority compared to other antipsychotic drugs in treatment-resistant schizophrenia $(\mathrm{TRS})^{17,18}$ and superior antisuicidal properties in SCZ. ${ }^{19}$ Despite this, it is frequently underutilized worldwide ${ }^{20}$ because of its severe, ${ }^{21}$ minor $^{22}$ or rare ${ }^{23,24}$ acute adverse events and its medium-long term cardiometabolic and hematological consequences. ${ }^{25,26}$

Therefore, it is important to increase our knowledge about the long-term management of clozapine treatment in order to facilitate side-effects prevention, particularly in the susceptible and often medically compromised TRS population. $^{27}$

The aim of the present study was to evaluate the safety of 5-year treatment with clozapine in chronic TRS patients in an inpatient setting.

\section{Materials and Methods}

\section{Patients and Procedures}

This was a prospective observational study using data from patients recruited from an inpatient long-term facility clinic located in Cotronei (Calabria, Italy). All participants were eligible if they were: (1) able to read and understand the informed consent form; (2) diagnosed with SCZ by an experienced psychiatrist according to the DSM-5 criteria; ${ }^{28}$ (3) ill for more than ten years; (4) fulfilling TRS criteria; ${ }^{29}$ (5) continuously receiving clozapine for the management of schizophrenia starting before entering the follow-up and for the whole duration of the observation; (6) clozapine initiation within 6 months before first study observation; (7) experiencing no relapse for at least six months before the study entry; (8) IQ $>70$; and (9) free of any serious neurological or medical condition. All participants who met the following criteria were excluded: (1) recent or uncertain diagnosis; (2) any other comorbid psychiatric disorder apart from SCZ (ie, affective disorders, anxiety disorders, obsessive-compulsive disorder, acute psychosis and other psychotic disorders) according to DSM-5 criteria, ${ }^{30}$ formulated through the Structured Clinical Interview for DSM-5 (SCID-5-CV), ${ }^{31}$ and repeated annually; (3) medical history and chart data that were implausible or undocumented; (4) drug abuse or dependence in the previous 12 months; and (5) history of a medical or neurological disease that could affect cognitive function.

Overall, all 189 inpatients hospitalized in the clinic were screened for study participation: 91 of them were not eligible because they were not affected by SCZ. Of the remaining 98, 77 were not eligible for the study because did not fully meet the criteria for TRS $(n=34)$, had not taken clozapine continuously $(n=25)$, or had insufficient available clinical data in the past five years $(n=18)$. The final sample was made up of 21 participants who were recruited for this study (Figure 1).

The study was approved by the Institutional Review Board of the Correnti-Centri Assistenziali Mons. Oliveti clinic. Participants were provided with a complete description of the study's aims and methods, and they gave informed consent to participate in the study before any procedure took place. Data collected covered a 5-year period from January 2015 to December 2019. The study protocol and procedures complied with ethical principles set out in the revised version of the Helsinki Declaration. $^{32}$

\section{Measures}

All participants had monthly clinical follow-up visits and were evaluated by means of the following tests, administrated by expert clinicians every six months during follow-up visits: 

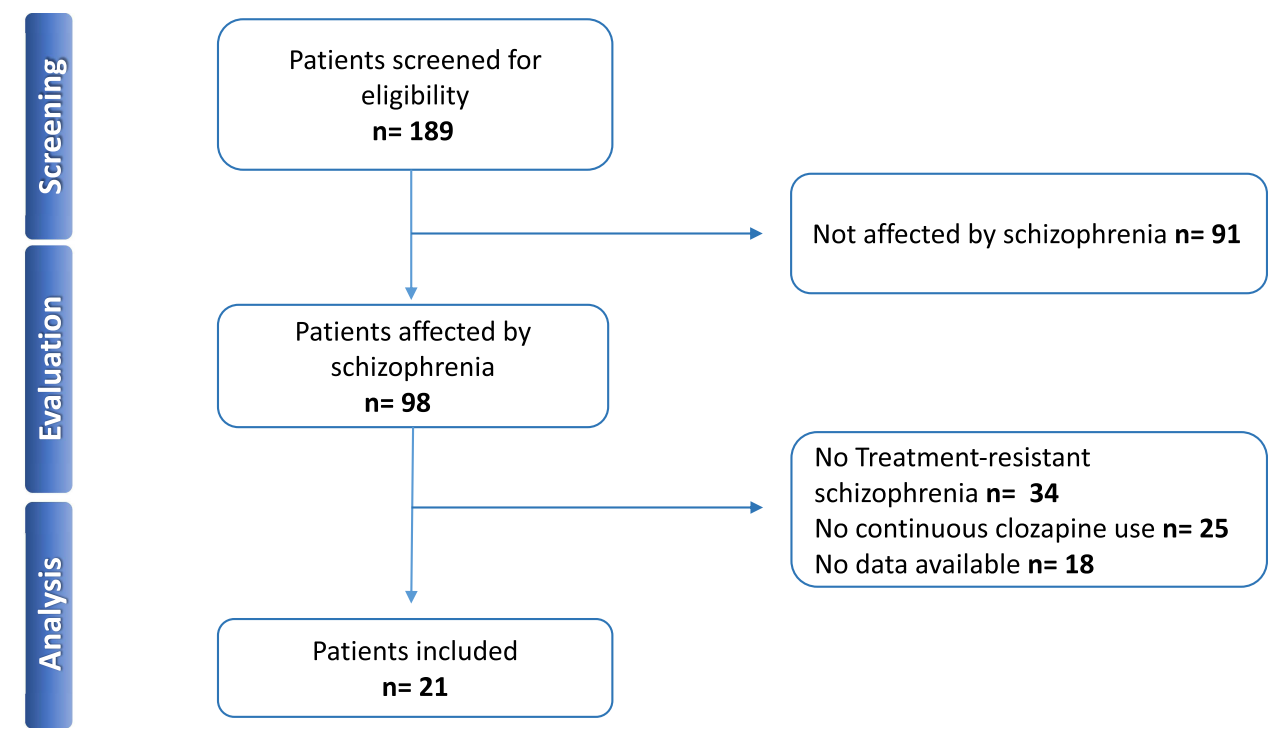

Figure I Sample Flow-Chart.

\section{Clinical Assessment}

- The psychosis severity rating scale (BPRS): ${ }^{33}$ a rateradministered 18-item scale ranging from 1 (“absent") to 7 ("very severe") for each question, with a total score from 18 to 126 . It is one of the most widely used clinician rating scales to evaluate treatment change across a comprehensive set of common symptoms, which include positive and negative symptoms, disorganization, affective symptoms and general psychopathology. ${ }^{34}$

- Glasgow Antipsychotic Side-effect Scale for Clozapine (GASS-C) ${ }^{35}$ a validated and reliable clinical tool for systematic assessment of the subjectively unpleasant side-effects of clozapine. The GASS-C version includes 16 questions: for each side effect of clozapine, patients indicated how often they had experienced that side effect in the past week (0-never, 1-once, 2-a few times, 3-everyday). Total scores are classified as: $0-16$ absent or mild side-effects, 17-32 moderate, and 33-48 severe side effects. The scale also includes a specific section that can be filled out if the individual considers the side effects to be disturbing, regardless of the frequency with which it occurred. The scale also contains a section about smoking and drinking coffee, and whether these habits have changed while taking clozapine, and another one about co-medications. ${ }^{36}$

\section{Social Functional Assessment}

- Social Performance Scale (PSP): ${ }^{37}$ a 100-point single-item rating scale, divided into 10 equal decimal intervals. It is a clinical tool for evaluating social functioning in rehabilitation settings. The rating assesses four main areas of patient's functioning: 1) socially useful activities; 2) personal and social relationships; 3) self-care; and 4) aggressive behaviors. Impairment in each area is rated on a single item using a six-point scale: Absent; Mild; Manifest but not marked; Marked; Severe; or Very severe, where lower ratings indicate better functioning. ${ }^{38}$

\section{Cognitive Assessment}

- Short Portable Mental Status Questionnaire (SPMSQ): ${ }^{39}$ a short, validated, reliable instrument to detect the presence of cognitive impairment and to determine its degree in elderly patients. It is a 10 -item tool, easily administered by any clinician in the ambulatory care or long-term inpatient settings. The total SPMSQ score is calculated from the total of errors based on a 10-item question list by coding errors as " 1 " and correct answers as " 0 ". Therefore, the final score ranged from 0 to 10 points, with lower values indicating better cognitive performance. Items include questions on attention (“Can you count backward from 20 by 3's?"), memory ("What is your phone number?") and orientation ("What are the date, month, and year?"). ${ }^{40}$ 
Patients underwent a structured and balanced diet established for them by a dietician, tailored to daily calories needed, comorbidities, age, weight and height. Moreover, each patient was engaged in moderate physical activity following a personalized training schedule with weekly in- and outdoor activities, performed with the help of the clinic staff. Experienced nurse staff was responsible for adhering to the required diet and physical activity protocols.

In addition, vital signs (pulse, cardiac frequency, temperature, blood pressure, height, weight, waist circumference, Body Mass Index (BMI)), electrocardiogram (EKG), blood tests (cell blood count (CBC), electrolytes, liver and thyroid function, lipid levels, glucose, serum iron), urine test and toxicology screen, clinical (eg, psychopharmacological therapy) and socio-demographic data have been collected monthly during each follow-up in person visit.

\section{Statistical Analysis}

Data were analyzed using the Statistical Package for Social Sciences Version 26.0 (SPSS, Chicago, Illinois, USA). Descriptive statistics included frequencies and percentages, means and standard deviations, as appropriate. To determine differences across the time General Linear Model (GLM), repeated measures were utilized, considering time (baseline and following every 12-months observations) and clozapine dosage as fixed factors. Eta-squared $\left(\eta^{2}\right)$, a measure of effect size, has been calculated for all significant findings. All tests have been two-sided, and the level of statistical significance was set at $\mathrm{p} \leq 0.05$.

\section{Results}

Demographics and clinical characteristics of the sample are described in Table 1. The final sample included twenty-one patients (16 males, 76\%) with an average age of 57.6 years, all affected by TRS and with continuous use of clozapine (mean dose $266 \mathrm{mg} /$ day). Of the total sample, eleven received at least one co-medication (eg, valproate, aripiprazole, haloperidol) and thirteen had physical comorbidities (eg, hypertension, diabetes mellitus II, thyroid disease). Concomitant medication treatment and clinical data were evaluated at the beginning, during and at the end of the observation period, and did not undergo any significant changes during the 5-year follow-up.

Table 2 displays results of GLM repeated measures for BPRS, PSP and SPMSQ. We found no statistically significant differences, both with time and mean clozapine dose as variable, in BPRS $(p=0.774 ; p=0.585)$, PSP $(p=0.855$;
Table I Demographics and Clinical Characteristics of the Sample at the End of the Study

\begin{tabular}{|c|c|c|c|}
\hline & & $\mathbf{F r}$ & $\%$ \\
\hline \multicolumn{4}{|l|}{ Demographics characteristics } \\
\hline \multirow[t]{2}{*}{ Gender } & Male & 16 & 76 \\
\hline & Female & 5 & 24 \\
\hline Age* & & 57.6 & 7.0 \\
\hline Education (years)* & & 8.2 & 2.7 \\
\hline \multirow[t]{3}{*}{ Civil status } & Single & 19 & 90 \\
\hline & Married & 1 & 5 \\
\hline & Divorced & I & 5 \\
\hline Occupation & Civil disability & 21 & 100 \\
\hline Smoking & (yes) & 14 & 67 \\
\hline Cigarettes/day* & & 16.8 & 4.6 \\
\hline Coffees/day* & & 4.2 & 1.3 \\
\hline \multicolumn{4}{|l|}{ Clinical characteristics } \\
\hline Diagnosis & TRS & 21 & 100 \\
\hline Years of disease* & & 33.4 & 7 \\
\hline $\begin{array}{l}\text { Length of hospitalization } \\
\text { (months)* }\end{array}$ & & 201.3 & 59.5 \\
\hline Clozapine (mg/day)* & & 266 & 135 \\
\hline $\begin{array}{l}\text { Length of clozapine treatment } \\
\text { (months)* }\end{array}$ & & 63.2 & 2.1 \\
\hline Comedication & Yes & II & 52 \\
\hline \multirow[t]{4}{*}{ Comedication (mg/day)* } & Valproate & 1125.0 & 250.0 \\
\hline & Clonazepam & 1.2 & 0.8 \\
\hline & Aripiprazole & 12.5 & 5.0 \\
\hline & Haloperidol & 5.0 & 0.2 \\
\hline \multirow[t]{10}{*}{ Comorbidities } & None & 8 & 38 \\
\hline & Hypertension & 5 & 24 \\
\hline & Diabetes & 3 & 14 \\
\hline & Mellitus II & & \\
\hline & Thyroid disease & I & 5 \\
\hline & Prostate disease & 1 & 5 \\
\hline & Dyslipidemia & 1 & 5 \\
\hline & Cardiomyopathy & I & 5 \\
\hline & Bilateral & I & 5 \\
\hline & Hypoacusis & & \\
\hline
\end{tabular}

Notes: *Data are presented as mean and standard deviation (SD). Age is provided in years; clozapine daily dose is provided in $\mathrm{mg} /$ day.

Abbreviations: $\mathrm{Fr}$, frequency; TRS, treatment-resistant schizophrenia.

$p=0.467)$, SPMSQ $(p=0.066 ; p=0.105)$ and GASS-C ( $p=0.546 ; p=0.342)$ values. The most commonly encountered side effects were constipation, sedation and hypersalivation. 
Table 2 Results of GLM Repeated Measures for BPRS, PSP, SPMSQ and GASS-C

\begin{tabular}{|c|c|c|c|c|c|c|}
\hline & $t_{i}$ & $t_{f}$ & $\Delta\left(t_{f}-t_{i}\right)$ & & $\mathbf{F}$ & $p$ \\
\hline BPRS & $30.0 \pm 8.0$ & $33.4 \pm 6.1$ & $3.4 \pm 1.9$ & $\begin{array}{c}\text { Time } \\
\text { CLZ dose }\end{array}$ & $\begin{array}{l}F(9, I I)=.600 \\
F(9, I I)=.857\end{array}$ & $\begin{array}{l}0.774 \\
0.585\end{array}$ \\
\hline PSP & $2.2 \pm 1.0$ & $1.9 \pm 0.9$ & $-0.3 \pm 0.1$ & $\begin{array}{c}\text { Time } \\
\text { CLZ dose }\end{array}$ & $\begin{array}{l}F(9, I I)=.488 \\
F(9, I I)=I .04 I\end{array}$ & $\begin{array}{l}0.855 \\
0.467\end{array}$ \\
\hline SPMSQ & $8.3 \pm 2.2$ & $7.9 \pm 2.4$ & $-0.4 \pm 0.2$ & $\begin{array}{c}\text { Time } \\
\text { CLZ dose }\end{array}$ & $\begin{array}{l}F(9, I I)=2.646 \\
F(9, I I)=2.236\end{array}$ & $\begin{array}{l}0.066 \\
0.105\end{array}$ \\
\hline GASS-C & $11.3 \pm 2.1$ & $12.4 \pm 4.8$ & $1.1 \pm 2.7$ & $\begin{array}{c}\text { Time } \\
\text { CLZ dose }\end{array}$ & $\begin{array}{c}F(9, I I)=.719 \\
F(9, I I)=1.128\end{array}$ & $\begin{array}{l}0.546 \\
0.342\end{array}$ \\
\hline
\end{tabular}

Abbreviations: BPRS, Brief Psychiatric Rating Scale; CLZ, clozapine; GASS-C, Glasgow Antipsychotic Side-effect Scale for Clozapine; GLM, General Linear Model; PSP, Social Performance Scale; SPMSQ, Short Portable Mental Status Questionnaire; $t_{i}$, baseline; $t_{f}$, study conclusion.

Supplementary Table 1 shows blood work findings over time and mean clozapine dose across the 5-year observational period. No significant differences were found in white blood cells, neutrophils, eosinophils, lymphocytes, platelets, hemoglobin, hematocrit, and mean cell volume in the sample. There were no cases of agranulocytosis reported in this sample. Only red blood cells showed a significant reduction over time $\left(\mathrm{p}=0.024 ; \eta^{2}=\right.$ 0.952).

Finally, Supplementary Table 2 illustrates the results of the GLM repeated measures for clinical parameters. No significant differences emerged across time and controlling for CLZ dose on all variables investigated, including heart activity (ie, heart rate and QTc interval), metabolic variables (ie, glycemia, cholesterol, HDL, LDL, triglycerides), liver (ie, AST, ALT) and kidney function (ie, creatinine, eGFR).

The most significant result was achieved with a mean weight reduction $(-8.98 \mathrm{~kg} \pm 14.31 \mathrm{~kg})$ and consequently with a mean BMI $\left(-3.0 \mathrm{~kg} / \mathrm{m}^{2}, p=0.008\right)$ between baseline and 5-years last observation (Figure 2).

\section{Discussion}

Despite clozapine being the only antipsychotic drug with proven efficacy in TRS, ${ }^{41,42}$ for suicidality in $\mathrm{SCZ}^{19}$ and its efficacy to reduce substance use in these patients, ${ }^{43}$ its use is still limited, and only $5 \%-20 \%$ of clozapine-eligible patients receive clozapine treatment. ${ }^{44}$ Indeed, clozapine is still extremely underprescribed by psychiatrists, ${ }^{20,45}$ introduced with considerable delay ${ }^{46}$ or stopped early. ${ }^{47}$ This is largely due to its disturbing side effect profile, with common and life-threatening side effects, ${ }^{48}$ and metabolic adverse events, ${ }^{49}$ as well as a range of minor reactions. ${ }^{21,22}$
Therefore, successful management strategies to facilitate long-term tolerability of clozapine are necessary ${ }^{50}$ in order to improve its pattern of use, especially in the often medically compromised TRS population. ${ }^{27}$

Our sample consisted mainly of men, unmarried, smokers, with a low educational level and a long history of illness. These findings are comparable with what is known in the literature for TRS population worldwide. ${ }^{51}$ Moreover, more than $50 \%$ had at least one other comedication, and in almost two thirds of the cases, a general medical comorbidity. Also, these data do not differ from previous report on the medical profile for TRS patients. $^{52,53}$ We found a mean clozapine dose of $266 \mathrm{mg} /$ day $(\mathrm{SD} \pm 135)$, and our outcomes are consistent with other reports. ${ }^{54,55}$ Thus, although our sample is small, it appears to be representative of the TRS population reported in the literature. ${ }^{56}$

There were no statistically significant differences, both if considering the time and the dosage of clozapine as variables, in BPRS, PSP, SPMSQ, and GASS-C values. This may be due to the small sample. However, we were able to find a worsening trend in BPRS $(\Delta 3.4 \pm 1.9)$, whereas there was a trend towards an improvement in PSP $(\Delta-0.3 \pm 0.1)$ and SPMSQ $(\Delta-0.4 \pm 0.2)$ over time. The data on psychopathological deterioration are surprising, since clozapine has been shown to be superior in the control of both negative and positive long-term symptoms. ${ }^{18}$ However, this could be explained by the natural history of the disorder and the progressive deterioration due to the patients' long history of illness. ${ }^{57} \mathrm{On}$ the other hand, our data on social functioning and cognitive improvement are in line with the international literature. ${ }^{58-60}$ On this regard, it is hard to say if the 


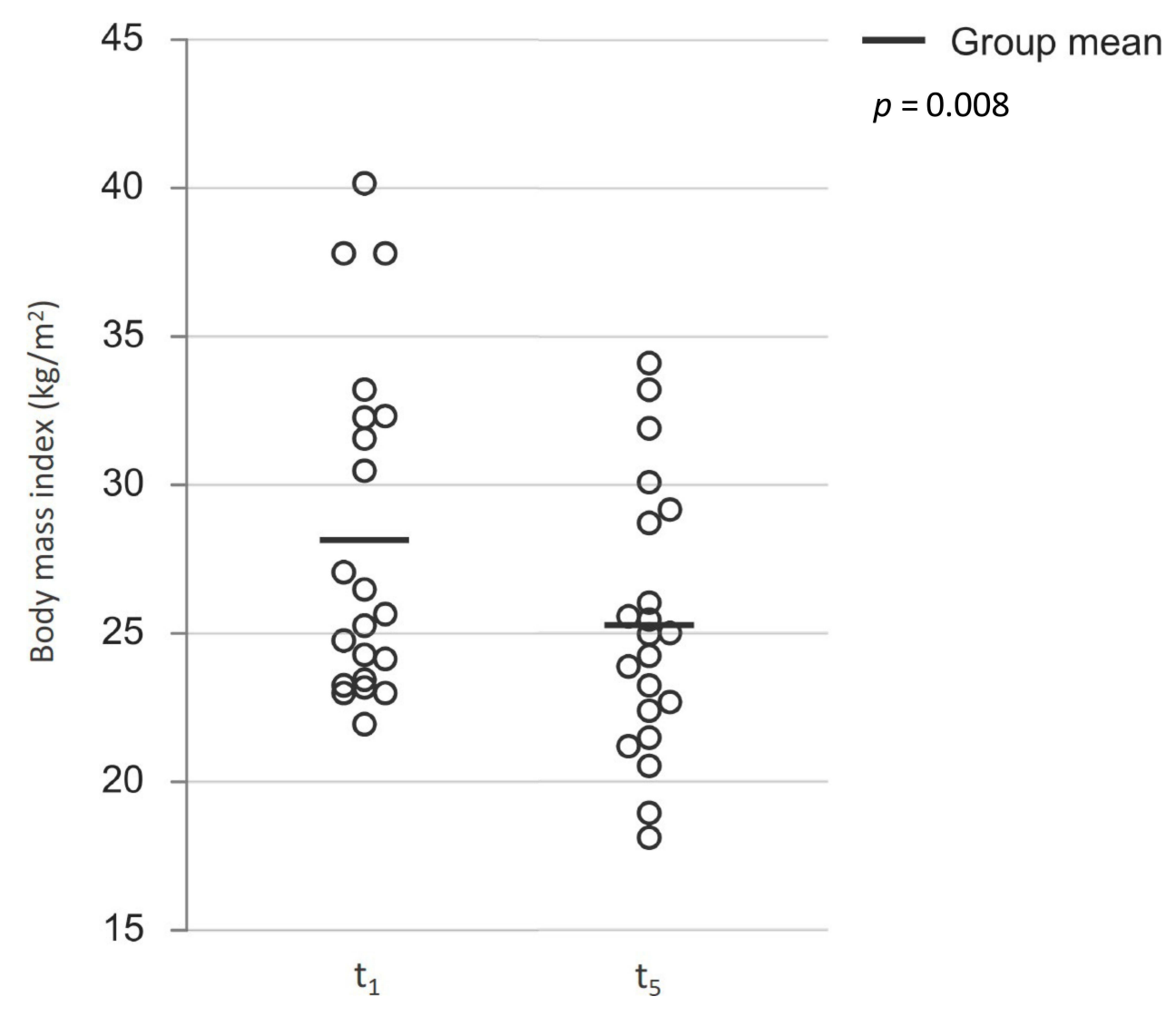

Figure 2 Changes in BMI.

participation in the study along with personalized training and close contact with long-term facilities staff had some relationships with this improvement in cognitive function. However, this is not completely surprising, since also previous research found that greater service intensity is related to higher rates of improvement in neurocognition and global functioning over time. ${ }^{61-63}$

Regarding blood work and cell blood count, we did not find any statistically significant difference for any cell count, except for a reduction over time in red blood cells $(\Delta-0.4 \pm 0.0)$.

All cell lines presented substantial stability, except for eosinophils, which showed a tendency to decrease over time, although not statistically significant $(p=0.406)$. The hematological effects of clozapine have been extensively studied, especially in the short term, reporting elevations in WBC, neutrophils, eosinophils, platelets and, to a lesser extent, basophils but no changes in RBC and lymphocytes. ${ }^{64}$ These findings are usually transient and typical of the initial stages, before settling over time, ${ }^{64,65}$ which would support our results. On the other hand, the evidence in the long run is less strong, with several studies reporting a substantial neutrophil reduction in the long run, which we have not found in our sample. ${ }^{66,67}$

We did not find any significant clinical worsening reflected in all variables investigated, including heart activity (ie, heart rate and QTc interval), metabolic variables (glycemia, cholesterol, HDL, LDL, triglycerides), liver (ie, GOT, GPT) and kidney function (ie, creatinine, eGFR). Therefore, patients did not develop metabolic and systemic complications. On the contrary, they showed a tendency to improve heart rate, cholesterol, LDL, TG, eGFR, AST and ALT values compared to baseline. This finding of stable metabolic state, and even improvement in BMI, is rather surprising and not in accordance with the known reported data in which clozapine and olanzapine are both associated with a higher tendency for metabolic disturbances. ${ }^{68}$ Previous epidemiological and naturalistic studies had confirmed a high tendency of SC patients to develop metabolic syndrome, especially if undergoing treatment with clozapine, with a rate above $50 \% .{ }^{69-71}$ However, the role of long-term hospitalization in care facilities could be decisive in positively influencing these outcomes, and it has not been deeply investigated before. 
However, these results must also be interpreted in light of the low sample size and the possibility of an inadvertent enrollment of patients who may tend to be resistant to the metabolic side effects of second-generation antipsychotic drugs. $^{49,72,73}$

Tolerability has remained good over time and the most common side effects have been non-serious and sporadic, such as constipation, sedation and hypersalivation, as is well known for clozapine. ${ }^{48,74}$

Finally, BMI showed the most important and statistically significant improvement in our sample. These findings are in opposition to clozapine propensity to induce weight gain and general metabolic dysregulation, ${ }^{75,76}$ but reflect the structured and balanced diet to which inpatients were subjected. Indeed, most of the reports of clozapineinduced weight gain are from naturalistic studies. ${ }^{77-79}$ In particular, a five-year naturalistic study reported significant weight gain and lipid abnormalities, related to an increased risk for developing diabetes, in a sample of 82 outpatients affected by schizophrenia or schizoaffective disorder. ${ }^{76}$ The significant differences compared to the metabolic results of our study further highlight the importance of a structured management of both diet and physical exercise in patients treated with antipsychotic drugs, in particular with those most indicated for metabolic adverse effects, such as clozapine. In addition, obesity in severe mental disorders can be attributed to an unhealthy lifestyle, poor physical activity as well as unbalanced diet. $^{80,81}$ Therefore, the results of our sample emphasize that adequate health care and lifestyle interventions can reduce the impact of disease and treatment on patients' cardiometabolic health, as previously reported. ${ }^{82,83}$ However, this underscores the decisive role the environment plays in TRS population outcomes, and the need to control this over the long term. Still, in order to understand the results of our study we must also consider potential differences in individual responses to clozapine. Indeed, recent studies have shown that different genetic profiles, as well as the clozapine-to-norclozapine ratio, might be associated with metabolic abnormalities and different responses to treatment in clozapine-treated patients affected by TRS, for both cardiometabolic outcomes and cognitive functioning. ${ }^{84,85} \mathrm{~A}$ recent Cochrane metaanalysis compared the efficacy and tolerability of clozapine at different dosages in psychotic disorders, including SCZ. ${ }^{55}$ Considering metabolic side effects, the authors concluded that BMI measurements were similar between groups in the short term, although weight gain was less at very low dose compared to standard dose in one study. They emphasized that there was a particular lack of medium- or long-term outcome data on this topic.

Although our results provide a different perspective on the long-term management of clozapine in TRS population, the present study has some limitations. First, a larger sample size would have provided additional statistical power; however, we were hampered to include more patients, as TRS rates are less than a third of the total SCZ population, ${ }^{86}$ itself with an incidence of less than $1 \%$ of the general population worldwide. ${ }^{87}$ Second, our results are derived from an observational study, and outcomes should be confirmed in a randomized controlled clinical trial. Third, there is the lack of clozapine plasma level, which could raise doubts about drug adherence. However, drugs plasma levels are not usually assessed in long-term facilities since adherence to treatment, as well as to diet and physical activities, are confirmed by careful daily drug administration by experienced healthcare professionals. Finally, the long-term clinical setting represents an ideal location for dietetic, clinical and pharmacological management, very different if compared to the real world everyday clinical practice.

\section{Conclusion}

The results of our study demonstrate how the application of a structured dietary, clinical and therapeutic monitoring program in psychiatric long-term care facilities allows the safe and effective management of clozapine, even from a long-term perspective. The unique role that clozapine plays in the current treatment of patients with TRS requires greater clinical awareness. Although its acute and chronic side effects are notorious, its safety management is feasible and broadens its potential practical application.

\section{Funding}

No funding was provided for this work.

\section{Disclosure}

Dr. Kane has been a consultant and/or advisor for or has received honoraria from Alkermes, Allergan, LB Pharmaceuticals, H. Lundbeck, Intracellular Therapies, Janssen Pharmaceuticals, Johnson and Johnson, Merck, Minerva, Neurocrine, Newron, Otsuka, Pierre Fabre, Reviva, Roche, Saladex, Sumitomo Dainippon, Sunovion, Takeda, Teva and UpToDate and is a shareholder in LB Pharmaceuticals and Vanguard Research Group. Drs de 
Filippis, Gaetano, Schoretsanitis, Verde, Oliveti, SeguraGarcia and De Fazio report no conflicts of interest in this work.

\section{References}

1. Kahn RS, Sommer IE, Murray RM, et al. Schizophrenia. Nat Rev Dis Prim. 2015;1:15067. doi:10.1038/nrdp.2015.67

2. van Os J, Kapur S. Schizophrenia. Lancet. 2009;374(9690):635-645. doi:10.1016/S0140-6736(09)60995-8

3. Huhn M, Nikolakopoulou A, Schneider-Thoma J, et al. Comparative efficacy and tolerability of 32 oral antipsychotics for the acute treatment of adults with multi-episode schizophrenia: a systematic review and network meta-analysis. Lancet. 2019;394(10202):939-951. doi:10.1016/S0140-6736(19)31135-3

4. Zink M, Englisch S. Schizophrenia Treatment: an Obstacle Course. lancet Psychiatry. 2016;3(4):310-312. doi:10.1016/S2215-0366(16) 00023-7

5. de Filippis R, De Fazio P, Gaetano R, et al. Current and emerging long-acting antipsychotics for the treatment of schizophrenia. Expert Opin Drug Saf. 2021:1-20. doi:10.1080/14740338.2021.1910674

6. Leucht S, Cipriani A, Spineli L, et al. Comparative efficacy and tolerability of 15 antipsychotic drugs in schizophrenia: a multiple-treatments meta-analysis. Lancet. 2013;382 (9896):951-962. doi:10.1016/S0140-6736(13)60733-3

7. Howes OD, Kapur S. The dopamine hypothesis of schizophrenia: version III--the final common pathway. Schizophr Bull. 2009;35 (3):549-562. doi:10.1093/schbul/sbp006

8. Oehl M, Hummer M, Fleischhacker W. Compliance With Antipsychotic Treatment. Acta Psychiatr Scand Suppl. 2000;1 (407):83-86. doi:10.1034/J.1600-0447.2000.00016.X

9. Widschwendter CG, Kemmler G, Rettenbacher MA, YalcinSiedentopf N, Hofer A. Subjective well-being, drug attitude, and changes in symptomatology in chronic schizophrenia patients starting treatment with new-generation antipsychotic medication. BMC Psychiatry. 2018;18(1):212. doi:10.1186/s12888-018-1791-y

10. O'Donoghue B, Francey SM, Nelson B, et al. Staged treatment and acceptability guidelines in early psychosis study (STAGES): a randomized placebo controlled trial of intensive psychosocial treatment plus or minus antipsychotic medication for first-episode psychosis with low-risk of self-harm or aggression. Study protocol and baseline characteristics of participants. Early Interv Psychiatry. 2019;13(4):953-960. doi:10.1111/eip.12716

11. Magliocco F, de Filippis R, Aloi M, et al. Second-generation long-acting injections anti-psychotics improve executive functions in patients with schizophrenia: a 12-month real-world study. Int J Psychiatry Clin Pract. 2020;24(2):201-207. doi:10.1080/ 13651501.2020.1737134

12. Hui C, Wong A, Leung W, et al. Psychiatrists' Opinion Towards Medication Discontinuation in Remitted First-Episode Psychosis: a Multi-Site Study of the Asian Network for Early Psychosis. Early Interv Psychiatry. 2019;13(6):1329-1337. doi:10.1111/EIP.12765

13. López-Muñoz F, Alamo C, Cuenca E, Shen WW, Clervoy P, Rubio G. History of the discovery and clinical introduction of chlorpromazine. Ann Clin Psychiatry. 2005;17(3):113-135. doi:10.1080/10401230591002002

14. Shen WW. A history of antipsychotic drug development. Compr Psychiatry. 1999;40(6):407-414. doi:10.1016/s0010-440x(99)90082-2

15. Claghorn J, Honigfeld G, Abuzzahab FSS, et al. The risks and benefits of clozapine versus chlorpromazine. $J$ Clin Psychopharmacol. 1987;7(6):377-384. doi:10.1097/00004714198712000-00002
16. Kane J, Honigfeld G, Singer J, Meltzer H. Clozapine for the treatment-resistant schizophrenic. A double-blind comparison with chlorpromazine. Arch Gen Psychiatry. 1988;45(9):789-796. doi:10.1001/archpsyc. 1988.01800330013001

17. Lally J, Gaughran F, Timms P, Curran SR. Treatment-resistant schizophrenia: current insights on the pharmacogenomics of antipsychotics. Pharmgenomics Pers Med. 2016;9:117-129. doi:10.2147/PGPM.S115741

18. Siskind D, McCartney L, Goldschlager R, Kisely S. Clozapine v. first- and second-generation antipsychotics in treatment-refractory schizophrenia: systematic review and meta-analysis. $\mathrm{Br}$ J Psychiatry. 2016;209(5):385-392. doi:10.1192/bjp.bp.115.177261

19. Zalsman G, Hawton K, Wasserman D, et al. Suicide Prevention Strategies Revisited: 10-year Systematic Review. Lancet Psychiatry. 2016;3(7):646-659. doi:10.1016/S2215-0366(16)30030-X

20. Okhuijsen-Pfeifer C, Cohen D, Bogers JPAM, et al. Differences between physicians' and nurse practitioners' viewpoints on reasons for clozapine underprescription. Brain Behav. 2019;9(7):e01318. doi:10.1002/brb3.1318

21. Curto M, Girardi N, Lionetto L, Ciavarella GM, Ferracuti S, Baldessarini RJ. Systematic Review of Clozapine Cardiotoxicity. Curr Psychiatry Rep. 2016;18(7):68. doi:10.1007/s11920-016-0704-3

22. De Fazio P, Gaetano R, Caroleo M, et al. Rare and very rare adverse effects of clozapine. Neuropsychiatr Dis Treat. 2015;11:1995-2003. doi:10.2147/NDT.S83989

23. de Filippis R, Soldevila-Matías P, De Fazio P, et al. Clozapine-related drug reaction with eosinophilia and systemic symptoms (DRESS) syndrome: a systematic review. Expert Rev Clin Pharmacol. 2020:1-9. doi:10.1080/17512433.2020.1787831

24. de Filippis R, Soldevila-Matías P, Guinart D, et al. Unravelling cases of clozapine-related Drug Reaction with Eosinophilia and Systemic Symptoms (DRESS) in patients reported otherwise: a systematic review. J Psychopharmacol. 2021:026988112110215. doi:10.1177/ 02698811211021587

25. Ijaz S, Bolea B, Davies S, et al. Antipsychotic polypharmacy and metabolic syndrome in schizophrenia: a review of systematic reviews. BMC Psychiatry. 2018;18(1):275. doi:10.1186/s12888-018$1848-\mathrm{y}$

26. Himmerich H, Minkwitz J, Kirkby KC. Weight Gain and Metabolic Changes During Treatment with Antipsychotics and Antidepressants. Endocr Metab Immune Disord Drug Targets. 2015;15(4):252-260. doi:10.2174/1871530315666150623092031

27. Kelly DL, McMahon RP, Liu F, et al. Cardiovascular disease mortality in patients with chronic schizophrenia treated with clozapine: a retrospective cohort study. J Clin Psychiatry. 2010;71(3):304-311. doi:10.4088/JCP.08m04718yel

28. American Psychiatric Association. Diagnostic and Statistical Manual of Mental Disorders. 5th. Washington, DC; 2013.

29. Howes OD, McCutcheon R, Agid O, et al. Treatment-Resistant Schizophrenia: treatment Response and Resistance in Psychosis (TRRIP) Working Group Consensus Guidelines on Diagnosis and Terminology. Am J Psychiatry. 2017;174(3):216-229. doi:10.1176/ appi.ajp.2016.16050503

30. American Psychiatric Association. Diagnostic and Statistical Manual of Mental Disorders: DSM-5. fifth. Washington; 2013.

31. First MB. SCID-5-CV: Structured Clinical Interview for DSM-5 Disorders, Clinician Version. Washington, DC: American Psychiatric Association; 2016.

32. World Medical Association. World Medical Association Declaration of Helsinki: ethical principles for medical research involving human subjects. JAMA. 2013;310(20):2191. doi:10.1001/jama.2013.281053

33. Overall JE, Gorham DR. The Brief Psychiatric Rating Scale (BPRS): recent developments in ascertainment and scaling. Psychopharmacol Bull. 1988;24(1):97-99. 
34. Dazzi F, Shafer A, Lauriola M. Meta-analysis of the Brief Psychiatric Rating Scale - Expanded (BPRS-E) structure and arguments for a new version. $J$ Psychiatr Res. 2016;81:140-151. doi:10.1016/j. jpsychires.2016.07.001

35. Hynes C, Keating D, McWilliams S, et al. Glasgow Antipsychotic Side-effects Scale for Clozapine - Development and validation of a clozapine-specific side-effects scale. Schizophr Res. 2015;168(12):505-513. doi:10.1016/j.schres.2015.07.052

36. Ignjatović Ristić D, Cohen D, Obradović A, Nikić-đuričić K, Drašković $M$. The Glasgow antipsychotic side-effects scale for clozapine in inpatients and outpatients with schizophrenia or schizoaffective disorder. Nord $J$ Psychiatry. 2018;72(2):124-129. doi:10.1080/08039488.2017.1400097

37. Morosini PL, Magliano L, Brambilla L, Ugolini S, Pioli R, Development, reliability and acceptability of a new version of the DSM-IV Social and Occupational Functioning Assessment Scale (SOFAS) to assess routine social functioning. Acta Psychiatr Scand. 2000;101(4):323-329. doi:10.1111/j.1600-0447.2000.tb10933.x

38. Kawata AK, Revicki DA. Psychometric properties of the Personal and Social Performance scale (PSP) among individuals with schizophrenia living in the community. Qual Life Res. 2008;17 (10):1247-1256. doi:10.1007/s11136-008-9400-z

39. Pfeiffer E. A Short Portable Mental Status Questionnaire for the Assessment of Organic Brain Deficit in Elderly Patients†. $J \mathrm{Am}$ Geriatr Soc. 1975;23(10):433-441. doi:10.1111/j.1532-5415.1975. tb00927.x

40. Schönstein A, Wahl H-W, Katus HA, Bahrmann A. SPMSQ for risk stratification of older patients in the emergency department: an exploratory prospective cohort study. Z Gerontol Geriatr. 2019;52 (Suppl 4):222-228. doi:10.1007/s00391-019-01626-Z

41. Kane J, Honigfeld G, Singer J, Meltzer H. Clozapine for the Treatment-Resistant Schizophrenic. Arch Gen Psychiatry. 1988;45 (9):789. doi:10.1001/archpsyc.1988.01800330013001

42. Warnez S, Alessi-Severini S. Clozapine: a review of clinical practice guidelines and prescribing trends. BMC Psychiatry. 2014;14:102. doi:10.1186/1471-244X-14-102

43. Khokhar JY, Henricks AM, Sullivan EDK, Green AI. Unique Effects of Clozapine: a Pharmacological Perspective. Adv Pharmacol. 2018;82:137-162. doi:10.1016/bs.apha.2017.09.009

44. Olfson M, Gerhard T, Crystal S, Stroup T. Clozapine for Schizophrenia: state Variation in Evidence-Based Practice. Psychiatr Serv. 2016;67(2):152. doi:10.1176/APPI.PS.201500324

45. Rubio JM, Kane JM. How and when to use clozapine. Acta Psychiatr Scand. 2019;141(3):178-189. doi:10.1111/acps.13111

46. John AP, Ko EKF, Dominic A. Delayed Initiation of Clozapine Continues to Be a Substantial Clinical Concern. Can J Psychiatry. 2018;63(8):526-531. doi:10.1177/0706743718772522

47. Nielsen J, Correll CU, Manu P, Kane JM. Termination of clozapine treatment due to medical reasons: when is it warranted and how can it be avoided? J Clin Psychiatry. 2013;74(6):603-613. doi:10.4088/ JCP.12r08064

48. Citrome L, McEvoy J, Saklad S. Guide to the Management of Clozapine-Related Tolerability and Safety Concerns. Clin Schizophr Relat Psychoses. 2016;10(3):163-177. doi:10.3371/19351232.10.3.163

49. Hirsch L, Yang J, Bresee L, Jette N, Patten S, Pringsheim T. SecondGeneration Antipsychotics and Metabolic Side Effects: a Systematic Review of Population-Based Studies. Drug Saf. 2017;40(9):771-781. doi:10.1007/s40264-017-0543-0

50. Smith RC, Leucht S, Davis JM. Maximizing response to first-line antipsychotics in schizophrenia: a review focused on finding from meta-analysis. Psychopharmacology. 2019;236(2):545-559. doi:10.1007/s00213-018-5133-z
51. Jönsson L, Simonsen J, Brain C, Kymes S, Watson L. Identifying and characterizing treatment-resistant schizophrenia in observational database studies. Int J Methods Psychiatr Res. 2019;28(3):e1778. doi: $10.1002 / \mathrm{mpr} .1778$

52. Correll CU, Brevig T, Brain C. Exploration of Treatment-Resistant Schizophrenia Subtypes Based on a Survey of 204 US Psychiatrists. Neuropsychiatr Dis Treat. 2019;15:3461-3473. doi:10.2147/NDT. S234813

53. Correll CU, Brevig T, Brain C. Patient characteristics, burden and pharmacotherapy of treatment-resistant schizophrenia: results from a survey of 204 US psychiatrists. BMC Psychiatry. 2019;19(1):362. doi:10.1186/s12888-019-2318-x

54. Grover S, Chakrabarti S, Hazari N, Avasthi A. Effectiveness of electroconvulsive therapy in patients with treatment resistant schizophrenia: a retrospective study. Psychiatry Res. 2017;249:349-353. doi:10.1016/j.psychres.2017.01.042

55. Subramanian S, Völlm BA, Huband N. Clozapine dose for schizophrenia. Cochrane Database Syst Rev. 2017;6(6):CD009555. doi:10.1002/14651858.CD009555.pub2

56. Beck K, McCutcheon R, Stephenson L, et al. Prevalence of Treatment-Resistant Psychoses in the Community: a Naturalistic Study. $J$ Psychopharmacol. 2019;33:10. doi:10.1177/ 0269881119855995

57. Zipursky RB, Agid O. Recovery, not progressive deterioration, should be the expectation in schizophrenia. World Psychiatry. 2015;14(1):94-96. doi:10.1002/wps.20194

58. Correll CU, Rubio JM, Kane JM. What is the risk-benefit ratio of long-term antipsychotic treatment in people with schizophrenia? World Psychiatry. 2018;17(2):149-160. doi:10.1002/wps.20516

59. Buonocore M, Bosia M, Baraldi MA, et al. Achieving recovery in patients with schizophrenia through psychosocial interventions: a retrospective study. Psychiatry Clin Neurosci. 2018;72(1):28-34. doi:10.1111/pcn.12605

60. Vaessen T, Viechtbauer W, van der Steen Y, et al. Recovery from daily-life stressors in early and chronic psychosis. Schizophr Res. 2019;213:32-39. doi:10.1016/j.schres.2019.03.011

61. Molina JL, Thomas ML, Joshi YB, et al. Gamma oscillations predict pro-cognitive and clinical response to auditory-based cognitive training in schizophrenia. Transl Psychiatry. 2020;10(1):405. doi:10.1038/ s41398-020-01089-6

62. Stiekema APM, van Dam MT, Bruggeman R, et al. Facilitating recovery of daily functioning in people with a severe mental illness who need longer-term intensive psychiatric services: results from a cluster randomized controlled trial on cognitive adaptation training delivered by nurses. Schizophr Bull. 2020;46(5):1259-1268. doi:10.1093/schbul/sbz135

63. Brekke JS, Hoe M, Long J, Green MF, Neurocognition H. Social Cognition Influence Functional Change During Community-Based Psychosocial Rehabilitation for Individuals with Schizophrenia. Schizophr Bull. 2007;33(5):1247-1256. doi:10.1093/schbul/sbl072

64. Lee J, Takeuchi H, Fervaha G, et al. The Effect of Clozapine on Hematological Indices: a 1-Year Follow-Up Study. $J$ Clin Psychopharmacol. 2015;35(5):510-516. doi:10.1097/ JCP.0000000000000387

65. Coşar B, Taner ME, Eser HY, Altınöz AE, Tarhan R. Does switching to another antipsychotic in patients with clozapine-associated granulocytopenia solve the problem? Case series of 18 patients. J Clin Psychopharmacol. 2011;31(2):169-173. doi:10.1097/ JCP.0b013e31820e3d9d

66. Xiong Z, Cheng M, Zhu P, et al. Association of blood cell counts with the risk of olanzapine- or clozapine-induced dyslipidemia in Chinese schizophrenia patients. Hum Psychopharmacol. 2019;34(4): e2699. doi:10.1002/hup.2699 
67. Goto A, Yoshimi A, Nagai T, et al. Human neutrophils show decreased survival upon long-term exposure to clozapine. Hum Psychopharmacol. 2017;32(6):e2629. doi:10.1002/hup.2629

68. Siskind D, Gallagher E, Winckel K, et al. Does Switching Antipsychotics Ameliorate Weight Gain in Patients With Severe Mental Illness? A Systematic Review and Meta-analysis. Schizophr Bull. 2021. doi:10.1093/schbul/sbaa191

69. Malhi G, Adams D, Plain J, Coulston C, Herman M, Walter G. Clozapine and cardiometabolic health in chronic schizophrenia: correlations and consequences in a clinical context. Australas Psychiatry. 2010;18(1):32-41. doi:10.3109/10398560903254193

70. Lamberti J, Olson D, Crilly J, et al. Prevalence of the Metabolic Syndrome Among Patients Receiving Clozapine. Am J Psychiatry. 2006;163(7):1273-1276. doi:10.1176/APPI.AJP.163.7.1273

71. Brunero S, Lamont S, Fairbrother G. Prevalence and predictors of metabolic syndrome among patients attending an outpatient clozapine clinic in Australia. Arch Psychiatr Nurs. 2009;23(3):261-268. doi:10.1016/j.apnu.2008.06.007

72. Newcomer JW. Second-Generation (Atypical) Antipsychotics and Metabolic Effects. CNS Drugs. 2005;19(Supplement1):13. doi:10.2165/00023210-200519001-00001

73. Hirsch L, Patten SB, Bresee L, Jette N, Pringsheim T. Secondgeneration antipsychotics and metabolic side-effects: Canadian population-based study. BJPsych Open. 2018;4(4):256-261. doi:10.1192/bjo.2018.33

74. Schneider C, Corrigall R, Hayes D, Kyriakopoulos M, Frangou S. Systematic review of the efficacy and tolerability of clozapine in the treatment of youth with early onset schizophrenia. Eur Psychiatry. 2014;29(1):1-10. doi:10.1016/j.eurpsy.2013.08.001

75. Whitney Z, Procyshyn R, Fredrikson D, Barr A. Treatment of Clozapine-Associated Weight Gain: a Systematic Review. Eur J Clin Pharmacol. 2015;71(4):389-401. doi:10.1007/S00228-0151807-1

76. Henderson DC. Clozapine, diabetes mellitus, weight gain, and lipid abnormalities: a five-year naturalistic study. Am J Psychiatry. 2000;157(6):975-981. doi:10.1176/appi.ajp.157.6.975

77. Chue P, Cheung R. The impact of weight gain associated with atypical antipsychotic use in schizophrenia. Acta Neuropsychiatr. 2004;16(3):113-123. doi:10.1111/j.0924-2708.2004.00067.x
78. Covell N, Weissman E, Essock S. Weight gain with clozapine compared to first generation antipsychotic medications. Schizophr Bull. 2004;30:2. doi:10.1093/OXFORDJOURNALS.SCHBUL.A007074

79. Taylor D, McAskill R. Atypical Antipsychotics and Weight Gain--A Systematic Review. Acta Psychiatr Scand. 2000;101:6. doi:10.1034/ J.1600-0447.2000.101006416.X

80. Heald A, Martin J, Payton T, et al. Changes in Metabolic Parameters in Patients with severe mental illness over a 10-year period: a retrospective cohort study. Aust N Z J Psychiatry. 2017;51:1. doi: $10.1177 / 0004867415625817$

81. de Caluwé L, van Buitenen N, Gelan P, et al. Prevalence of metabolic syndrome and its associated risk factors in an African-Caribbean population with severe mental illness. Psychiatry Res. 2019:281. doi:10.1016/J.PSYCHRES.2019.112558

82. Naslund J, Aschbrenner K, Scherer E, Pratt S, Wolfe R, Bartels S. Lifestyle intervention for people with severe obesity and serious mental illness. Am J Prev Med. 2016;50(2):145-153. doi:10.1016/J. AMEPRE.2015.07.012

83. Looijmans A, Jörg F, Bruggeman R, Schoevers R, Corpeleijn E. Design of the Lifestyle Interventions for Severe Mentally Ill Outpatients in the Netherlands (LION) Trial; A Cluster Randomised Controlled Study of a Multidimensional Web Tool Intervention to Improve Cardiometabolic Health in Patients With Severe Mental I. BMC Psychiatry. 2017;17(1). doi:10.1186/S12888-017-1265-7

84. Chen P-Y, Lu M-L, Huang M-C, et al. The relationships of obesity-related genetic variants with metabolic profiles and response to metformin in clozapine-treated patients with schizophrenia. J Clin Psychopharmacol. 2015;35(5):574-578. doi:10.1097/ JCP.0000000000000386

85. Costa-Dookhan KA, Agarwal SM, Chintoh A, et al. The clozapine to norclozapine ratio: a narrative review of the clinical utility to minimize metabolic risk and enhance clozapine efficacy. Expert Opin Drug Saf. 2020;19(1):43-57. doi:10.1080/14740338.2020.1698545

86. Lally J, Gaughran F. Treatment resistant schizophrenia - review and a call to action. Ir J Psychol Med. 2019;36(4):279-291. doi:10.1017/ ipm.2018.47

87. McGrath J, Saha S, Chant D, Welham J. Schizophrenia: a concise overview of incidence, prevalence, and mortality. Epidemiol Rev. 2008;30:30. doi:10.1093/EPIREV/MXN001
Neuropsychiatric Disease and Treatment

\section{Publish your work in this journal}

Neuropsychiatric Disease and Treatment is an international, peerreviewed journal of clinical therapeutics and pharmacology focusing on concise rapid reporting of clinical or pre-clinical studies on a range of neuropsychiatric and neurological disorders. This journal is indexed on PubMed Central, the 'PsycINFO' database and CAS, and is the official journal of The International Neuropsychiatric Association (INA). The manuscript management system is completely online and includes a very quick and fair peer-review system, which is all easy to use. Visit http://www.dovepress.com/testimonials.php to read real quotes from published authors. 